\title{
A New Molecular Magnetic Semiconductor Based on Tetrathiafulvalene (ttf) and Oxamato Ligand (opba): $[\mathrm{ttf}]_{2}[\mathrm{Cu}(\mathrm{opba})] \cdot \mathrm{H}_{2} \mathrm{O}$
}

\author{
Mauro C. Dias, ${ }^{a}$ Humberto O. Stumpf, ${ }^{*, b}$ Raquel V. Mambrini, ${ }^{b}$ Tulio Matencio, ${ }^{b}$ \\ Maria T. C. Sansiviero ${ }^{b}$ and Marcelo Knobel ${ }^{c}$ \\ ${ }^{a}$ Coordenadoria de Ciências e Tecnologias Químicas, Centro Federal de Educação Tecnológica do \\ Espírito Santo, 29040-780 Vitória-ES, Brazil \\ ${ }^{b}$ Departamente de Química, ICEx, Universidade Federal de Minas Gerais, \\ 31270-901 Belo Horizonte-MG, Brazil \\ 'Instituto de Física Gleb Wataghin, Universidade Estadual Campinas, \\ 13083-970 Campinas-SP, Brazil
}

\begin{abstract}
Um composto de fórmula $[\mathrm{ttf}]_{2}[\mathrm{Cu}($ opba $)] \cdot \mathrm{H}_{2} \mathrm{O}$, com ttf $=$ tetrathiafulvaleno e opba $=$ orto-fenilenobis(oxamato), foi preparado e caracterizado. $\mathrm{O}$ complexo foi obtido por reação de metátese entre $(\mathrm{ttf})_{3}\left(\mathrm{BF}_{4}\right)_{2} \mathrm{e}\left(\mathrm{Bu}_{4} \mathrm{~N}\right)_{2}[\mathrm{Cu}(\mathrm{opba})] \mathrm{em}$ acetonitrila à temperatura ambiente. O espectro $\mathrm{UV}$-Vis-NIR mostra a presença do radical cátion em duas formas, $\left(\mathrm{ttf}^{\bullet+}\right)$ e dímero $\left(\mathrm{ttf}^{\bullet+}\right)_{2}$. As propriedades de condutividade de $[\mathrm{ttf}]_{2}\left[\mathrm{Cu}(\right.$ opba) $] \cdot \mathrm{H}_{2} \mathrm{O}$ foram estudadas por espectroscopia de impedância (IS) e voltametria linear (LV) e mostram um comportamento típico de semicondutor. $\mathrm{O}$ espectro de EPR exibe duas linhas superpostas correspondentes aos spins eletrônicos de íons $\mathrm{Cu}^{\mathrm{II}}$ e de radicais cátions $\mathrm{ttf}^{{ }^{*}}$. As propriedades magnéticas $(\mathrm{dc})$ mostram um valor do produto $\chi_{\mathrm{M}} \mathrm{T}$ na temperatura ambiente próximo ao esperado para três spins $\mathrm{S}=1 / 2$ desacoplados e um valor de 0.13 emu $\mathrm{K} \mathrm{mol}^{-1}$ a baixas temperaturas $(4 \mathrm{~K})$. A curva do produto $\chi_{\mathrm{M}} \mathrm{T}$ versus $\mathrm{T}$ foi ajustada e o melhor modelo consiste de um termo para o dímero (ttf $\left.{ }^{\bullet+}\right)_{2}$ (Bleaney-Bowers, resultando em $\left.\mathrm{J}_{2}=-186 \mathrm{~cm}^{-1}\right)$ e de um segundo termo relativo a uma cadeia antiferromagnética $\mathrm{Cu} \cdots \mathrm{ttf}{ }^{\bullet+}$ $\left(\mathrm{J}_{1}=-10.1 \mathrm{~cm}^{-1}\right)$.
\end{abstract}

An oxamato-based compound of formula $[\mathrm{ttf}]_{2}[\mathrm{Cu}(\mathrm{opba})] \cdot \mathrm{H}_{2} \mathrm{O}$, with $\mathrm{ttf}=$ tetrathiafulvalene and opba $=$ ortho-phenylenebis(oxamato), has been prepared and characterized. The complex was obtained by metathesis from $(\mathrm{ttf})_{3}\left(\mathrm{BF}_{4}\right)_{2}$ and $\left(\mathrm{Bu}_{4} \mathrm{~N}\right)_{2}[\mathrm{Cu}($ opba $)]$ in acetonitrile at room temperature. The UV-Vis-NIR spectrum reveals the presence of the radical cation in two forms, $\left(\mathrm{ttf}^{\bullet+}\right)$ and $\left(\mathrm{ttf}^{\bullet+}\right)_{2}$ dimer. The electronic transport properties of $[\mathrm{ttf}]_{2}[\mathrm{Cu}(\mathrm{opba})] \cdot \mathrm{H}_{2} \mathrm{O}$ were studied by impedance spectroscopy (IS) and linear voltammetry (LV), and show a typical semiconductor behavior. The EPR spectra exhibit two superposed lines corresponding to electron spins of $\mathrm{Cu}^{\mathrm{II}}$ ions and $\mathrm{ttf}^{\bullet+}$ radical cations. The dc magnetic properties show a room temperature value of the $\chi_{\mathrm{M}} \mathrm{T}$ product close to that expected for three uncoupled $S=1 / 2$ spins and a value of $0.13 \mathrm{emu} \mathrm{K} \mathrm{mol}{ }^{-1}$ at low temperature $(4 \mathrm{~K})$. The $\chi_{\mathrm{M}} \mathrm{T} v s$. T curve was fitted and the best model consists of a term for a $\left(\mathrm{ttf}^{\bullet+}\right)_{2}$ dimer (Bleaney-Bowers, leading to $\mathrm{J}_{2}=-186 \mathrm{~cm}^{-1}$ ) and a second term related to an antiferromagnetic $\left\{\mathrm{Cu} \cdots \mathrm{tff}^{\bullet+}\right\}$ chain $\left(\mathrm{J}_{1}=-10.1 \mathrm{~cm}^{-1}\right)$.

Keywords: tetrathiafulvalene, molecular magnetism, semiconductor, oxamato ligand, molecular spintronics

\section{Introduction}

In the last few decades, the search for a molecular equivalent of a given material has increased, owed to the possibility to incorporate a new property through organic

*e-mail: stumpf@ufmg.br or coordination compounds maintaining the features of the original system. In the area of electronic materials, for example, molecular conductors constitute a theme of large appeal, where ttf (tetrathiafulvalene, 2,2'-bi-1,3-dithiole) and its derivatives are by far the most investigated. $\mathrm{Ttf}$ is a $\pi$-electron donor capable to form radical $\left[\mathrm{ttf}^{\circ+}\right]$ species $^{1}$ and charge transfer complexes as the conductor $[\mathrm{ttf}] \mathrm{Cl}^{2}{ }^{2} \mathrm{In}$ 
1973, the first 1D metal [ttf-tcnq] (with tenq = tetra-cyano$p$-quinodimethane) was described. ${ }^{3}$ Its structure consists of stacks of either the tcnq or ttf planar molecules and there is a partial electron transfer from the donor to the acceptor forming the charge-transfer salt $[\mathrm{ttf}]^{\delta+}[\mathrm{tcnq}]^{\delta-},{ }^{4}$ which exhibits conductivity of $1.47 \times 10^{4} \mathrm{~S} \mathrm{~cm}^{-1}$ at $66 \mathrm{~K}$.

The next step in this challenge was the achievement of organic or molecular superconductors. This was attained with the derivative bedt-ttf or bis(ethylenedithio) tetrathiafulvalene in a series of compounds such as the $\kappa$-(bedt-ttf) ${ }_{2} \mathrm{Cu}\left[\mathrm{N}(\mathrm{CN})_{2}\right] \mathrm{Br}$ superconductor at $\mathrm{T}_{\mathrm{c}}=11.8 \mathrm{~K}$ under ambient pressure, ${ }^{5}$ or $\mathrm{\kappa}$-(bedt-ttf) ${ }_{2}$ $\mathrm{M}\left(\mathrm{CF}_{3}\right)_{4} \cdot\left(\mathrm{Cl}_{2} \mathrm{C}=\mathrm{CHCl}\right)$, where $\mathrm{M}=\mathrm{Cu}, \mathrm{Ag}, \mathrm{Au}$, showing $\mathrm{T}_{c}$ 's in the temperature range of $2.1-11 \mathrm{~K}^{6}$

In another branch of molecular materials, the moleculebased magnets have introduced a huge richness of theoretical viewpoints and potentialities to form new magnetic materials. A profusion of synthetic strategies to prepare systems with high critical temperatures has been developed. One of them is the complex as ligand. For instance, the diethylester $\mathrm{Et}_{2} \mathrm{H}_{2}$-opba proligand, with opba $=$ ortho-phenylenebis(oxamato), that our group has thoroughly employed, can be used to form a precursor or ligand such as $[\mathrm{Cu}(\mathrm{opba})]^{2-}$, suitable to bind to a variety of metal ions. The strategy to use $[\mathrm{Cu}(\mathrm{opba})]^{2-}$ as building block of molecule-based magnets was first proposed ${ }^{7}$ and effectively described ${ }^{8}$ in 1993 . Since that date, there was a concern with the design and synthesis of new molecular edifices, aiming to investigate their structure-properties correlations. This view point can be exemplified as follow: $\left[\mathrm{CoCu}(\mathrm{opba})(\mathrm{dmso})_{3}\right]$, a ferrimagnetic chain synthesized in dimethylsulfoxide (dmso) that presents, superposed to the linear birefringence, a very strong dichroism; ${ }^{9}$ $\mathrm{Na}_{2}\left[\mathrm{Co}_{2}\{\mathrm{Cu} \text { (opba) }\}_{3}\right] \cdot 2 \mathrm{dmso} \cdot 6 \mathrm{H}_{2} \mathrm{O}$, a two-dimensional magnet displaying a large coercive field and a cluster glass behavior; ${ }^{10}\left[\mathrm{Bu}_{4} \mathrm{~N}\right]_{2}\left[\mathrm{Co}_{2}\{\mathrm{Cu}(\text { opba })\}_{3}\right] \cdot \mathrm{dmf} \cdot \mathrm{H}_{2} \mathrm{O}$, a hard magnet (coercive field of $4 \mathrm{kOe}$ ) exhibiting the highest critical temperature in this family with $\mathrm{T}_{\mathrm{c}}$ around $40 \mathrm{~K} ;{ }^{11} \mathrm{a}$ family of magnets containing three types of spins carriers and interlocked structures $[\mathrm{R}-\mathrm{Rad}]_{2}\left[\mathrm{M}_{2}\{\mathrm{Cu}(\mathrm{opba})\}_{3}\right]$, where $\mathrm{R}-\mathrm{Rad}^{+}$is a 2-(N-alkyl)-pyridinium nitronyl nitroxide radical cation; 8,12 [3-MeRad $]_{2}\left[\mathrm{Mn}_{2}\{\mathrm{Cu}(\text { opba })\}_{3}\right]$. $6 \mathrm{dmso} \cdot 8 \mathrm{H}_{2} \mathrm{O}$ (with $3-\mathrm{MeRad}^{+}$being the 2-(3- $\mathrm{N}$-methylpyridinium)-4,4,5,5-tetramethylimidazoline-1-oxyl-3oxide), the first magnet within this family to display a 2D (honeycomb) non-interlocked structure and, consequently, a metamagnetic behavior $;^{13}$ the nanocomposite of $[\mathrm{CoCu}$ (opba)] incorporated in Vycor glass (PVG), consisting of ferrimagnetic chains limited by the nanopore size, which leads to a slow relaxation of the magnetization following Arrhenius law, frequency dependence, and hysteresis below the blocked regime temperature $(<6 \mathrm{~K})$, characteristic of single chain magnets. ${ }^{14}$ Besides the $[\mathrm{Cu}(\text { opba })]^{2-}$ strategy, new challenges concerning oxamato derivatives are open. We can make a slight change of the ligand to prepare a metamagnet as $\left[\mathrm{Co}_{2} \mathrm{Cu}_{2}(\mathrm{mpba})_{2}\left(\mathrm{H}_{2} \mathrm{O}\right)_{6}\right] \cdot 6 \mathrm{H}_{2} \mathrm{O}$, where $\mathrm{mpba}=$ meta -phenylenebis (oxamato), which exhibits a new corrugated brick-wall sheet structure and magnetic glassy behavior, ${ }^{15}$ or replace $\mathrm{Cu}^{\mathrm{II}}$ to prepare novel building blocks as $\left[\mathrm{Fe}\left(\mathrm{H}_{2}\right.\right.$ opba-i $\left.)(\mathrm{dmso})_{2}\right] \mathrm{Cl}$, with opba in an iminoalcohol tautomeric form. ${ }^{16}$

For a long time, molecular conductors and (ferro) magnets were seen as incompatible although both deal with the same strategy pointing towards multiproperties materials. The congregation of these two branches is of large interest for the spintronics field, which deals with properties as GMR (giant magnetoresistance) ${ }^{17}$ and MTJ (magnetic tunnel junction). ${ }^{18} \mathrm{~A}$ large number of examples of semiconductors $\left(\beta\right.$-(bedt-ttf) $\left.{ }_{2}\left[\mathrm{FeCl}_{4}\right]\right),{ }^{19}$ conductors ([bedt-ttf $]_{3}\left[\mathrm{CuCl}_{4}\right] \cdot \mathrm{H}_{2} \mathrm{O}$ ), ${ }^{20,21}$ and, in a minor scale, superconductors $\left(\beta \text {-(bedt-ttf) }{ }_{4}\left[\left(\mathrm{H}_{2} \mathrm{O}\right) \mathrm{Fe}\left(\mathrm{C}_{2} \mathrm{O}_{4}\right)_{3}\right] \cdot \mathrm{PhCN}\right)^{22,23}$ containing organic radicals and paramagnetic coordination compounds are found in the literature. The stacking of multilayers is the topological feature of the devices that already use the GMR or MTJ technologies with magnetic control of the flow of spin-polarized electrons. Indeed, a molecular construction of each thin layer with specific properties, promoting tailored interlayer interactions or maintaining isolation through organic or inorganic spacers represents a significant challenge to synthetic chemists.

Our group has worked with several planar building blocks and organic radicals that show the capability to form 2D networks, negatively or positively charged, which are candidates to contribute to the development of a molecular branch of spintronics. Recently, a magnetic molecular semiconductor based on a dithiolene ligand derivative and the nitronyl nitroxide radical cation was presented..$^{24}$ Herein we report the synthesis and properties of the first molecular semiconductor with the tetrathiafulvalene cation and a paramagnetic oxamato-based complex of formula $[\mathrm{ttf}]_{2}[\mathrm{Cu}(\mathrm{opba})] \cdot \mathrm{H}_{2} \mathrm{O}$.

\section{Experimental}

\section{Synthesis}

A solution of $(\mathrm{ttf})_{3}\left(\mathrm{BF}_{4}\right)_{2}{ }^{25}(0.200 \mathrm{~g}, 0.26 \mathrm{mmol})$ in acetonitrile $(60 \mathrm{~mL})$ was slowly added to a solution of $\left(\mathrm{Bu}_{4} \mathrm{~N}\right)_{2}[\mathrm{Cu}(\mathrm{opba})]^{8}(0.204 \mathrm{~g}, 0.26 \mathrm{mmol})$ in acetonitrile $(10 \mathrm{~mL})$. The resulting mixture was stirred for $15 \mathrm{~min}$, then allowed to stand at room temperature for $30 \mathrm{~min}$. The brown-red precipitate was filtered off and washed with 
acetonitrile. The product was dried under reduced pressure for $4 \mathrm{~h}$ (187 mg, yield: 95\%). Elemental Analysis: Calc. for $\mathrm{C}_{22} \mathrm{H}_{14} \mathrm{CuN}_{2} \mathrm{O}_{7} \mathrm{~S}_{8}, \mathrm{MM}=738.43 \mathrm{~g} \mathrm{~mol}^{-1}: \mathrm{C}, 35.79 ; \mathrm{H}$, 1.91 ; N, 3.79; S, 34.74; Cu, 8.60\%. Found: C, 36.45; H, $2.10 ; \mathrm{N}, 4.01 ; \mathrm{S}, 35.00 ; \mathrm{Cu}, 8.70 \%$.

\section{Physical measurements}

Infrared spectra were obtained by using a Fourier transform infrared spectrometer Galaxy 3030 model (Mattson Instrument) with DTGS (deuterated triglycine sulphate) detector on $\mathrm{KBr}$ pellets. The UV-Vis-NIR absorption spectra were measured in a spectrophotometer Hewlett Packard model 8453 on pellets containing $0.4 \mathrm{mg}$ of the sample in $100 \mathrm{mg}$ of $\mathrm{KBr}$. The Raman spectra were obtained in a micro-Raman instrument (Renishaw System 3000) equipped with a CCD (charge-coupled device) detector. The $632.8 \mathrm{~nm}$ line of a He-Ne laser with $20 \mathrm{~mW}$ output power (5 $\mathrm{mW}$ at the sample) Spectra Physics Model 127 was employed as the exciting radiation.

Electron paramagnetic resonance (EPR) was carried out in a home-made spectrometer by using a cylindrical $\mathrm{X}$-band resonance cavity (Bruker) working at $9.4 \mathrm{GHz}$. Temperature variations were possible with a helium gas flow cryostat (Oxford) between 10 and $300 \mathrm{~K}$; temperatures were measured by a chromel constantan thermocouple. EPR spectra of powdered samples were obtained with usual field modulation of $100 \mathrm{kHz}$ and lock-in detection. The microwave power level was changed between $10 \mu \mathrm{W}$ and $100 \mathrm{~mW}$ and the modulation amplitude limit used was $H_{m} \leq 3.35 \mathrm{G}$ at $100 \mathrm{kHz}$. The absolute value of the normalized spin susceptibility, $\chi_{\text {spin }}$, was determined using as reference the signal of $\mathrm{CuSO}_{4} \cdot 2 \mathrm{H}_{2} \mathrm{O}$ (Aldrich, $6.00 \times 10^{-6} \mathrm{emu} \mathrm{g}^{-1}$ at $290 \mathrm{~K}$ ). The static susceptibility was measured on a SQUID magnetometer of Quantum Design (MPM SXL7) from 5 to $300 \mathrm{~K}$ applying a magnetic field of 500 Oe. The raw susceptibility data were corrected for the diamagnetism of the constituent atoms estimated as $-2.78 \times 10^{-4} \mathrm{emu} \mathrm{mol}^{-1}$ from the Pascal tables.

The resistance measurements were performed on the material pressed into pellets using a $5 \mathrm{MPa}$ charge (initially, it was checked that pressure had no effect on electrical resistance above this value) and known dimensions ( $\mathrm{A}=$ area and $\mathrm{L}=$ thickness). Measurements were carried out employing the impedance spectroscopy (IS) and linear voltammetry (LV) techniques, through which the cell conductivity could be determined respectively from the low frequency resistance of the impedance spectrum and from the slope of I-V curve. Measurements with the IS technique (FRA/AUTOLAB PGST30, $100 \mathrm{mV}$ ac perturbation, $10^{-1}$ $6 \times 10^{4} \mathrm{~Hz}$ frequency range) were carried out using the 89 -
$300 \mathrm{~K}$ temperature range. The electrical contacts consisted of two metallic layers (100 nm thick gold film) deposited on both sides of the pellet by sputtering (Kurt J. Lester 108) and were connected to metallic wires using silver paste. The impedance data (Nyquist plots: $-\operatorname{Im}(Z) v s . \operatorname{Re}(Z)$ ) were analyzed using Boukamp equivalent circuit software, ${ }^{26}$ from which $\mathrm{R}_{\mathrm{LF}}$ values (low frequency resistance) and CPE (constant phase element accounting for dielectric polarization) were deduced. Conductivity was calculated from $\mathrm{R}_{\mathrm{LF}}$ using the $\sigma_{\mathrm{LF}}=\mathrm{L} / \mathrm{R}_{\mathrm{LF}} \times \mathrm{A}$ expression. Concerning the LV technique, a KEITHLEY 237 Source Measure Unit was used, applying a dc potential and measuring the resulting current through the circuit. In the latter case, electrical side contacts were made by copper heads and silver paste. Temperature control between 300 and $4 \mathrm{~K}$ was achieved by means of a sensitive cryostat ( $\mathrm{mK}$ precision range at low temperature). Conductivity values were deduced from $\sigma_{\mathrm{dc}}=\mathrm{L} / \mathrm{R} \times \mathrm{A}$ relation where $\mathrm{R}=(\mathrm{d} / / \mathrm{dV})^{-1}$. For those samples that showed an $I=f(V)$ linear regime, $\mathrm{R}$ was obtained directly for the slope.

\section{Results and Discussion}

Attempts to obtain single crystals of the $[\mathrm{ttf}]_{2}[\mathrm{Cu}(\mathrm{opba})] \cdot \mathrm{H}_{2} \mathrm{O}$ compound by the metathetical reaction and by electrocrystallization were not successful.

The UV-Vis-NIR spectrum of $[\mathrm{ttf}]_{2}[\mathrm{Cu}(\mathrm{opba})] \cdot \mathrm{H}_{2} \mathrm{O}$ (Figure 1) shows three main absorption bands at 360, 540 and $780 \mathrm{~nm}$. The first band is attributed to $\pi-\pi^{*}$ transition of monomer $\mathrm{ttf}^{\cdot+}$, since the $\left(\mathrm{Bu}_{4} \mathrm{~N}\right)_{2}[\mathrm{Cu}($ opba) $)$ precursor and the $\left(\mathrm{ttf}^{\circ+}\right)_{2} \mathrm{dimer}^{27,28}$ have no bands in this region. The band at $540 \mathrm{~nm}$ is attributed to localized excitations inside each $\mathrm{ttf}^{\circ+}$ moiety of the dimer $\left(\mathrm{ttf}^{\circ+}\right)_{2}$. For the sake of comparison, this absorption is at $520 \mathrm{~nm}$ for the dimeric species in the (ttf) $\mathrm{ClO}_{4}$ conductor and corresponds to the main absorption at $580 \mathrm{~nm}$ of the monomeric species. ${ }^{27}$ The broad band centred at $780 \mathrm{~nm}$ is a characteristic feature of the charge-transfer (CT) transition between radicals in the dimer $\left(\mathrm{ttf}^{\cdot+}\right)_{2} \cdot{ }^{29}$ For salts such as $(\mathrm{ttf}) \mathrm{Br}_{1.0}$, this band is asymmetric (maximum at $730 \mathrm{~nm}$ ) and presents an intensity close to that of $530 \mathrm{~nm} .{ }^{28} \mathrm{~A}$ study of the polarized absorption spectrum of a single crystal of (ttf) $\mathrm{ClO}_{4}$ has suggested that the lower-energy CT band (spectrum parallel to the $a$-axis) observed at $833 \mathrm{~nm}$ is due to the intradimer CT transition and that at $667 \mathrm{~nm}$ is due to the interdimer $\mathrm{CT}$ transition. In addition, the intensities of these bands are different and the latter absorption is observed not only in the $a$-parallel spectrum but also in the $b$-parallel spectrum. ${ }^{30}$ For $[\mathrm{ttf}]_{2}[\mathrm{Cu}(\mathrm{opba})] \cdot \mathrm{H}_{2} \mathrm{O}$, a band broadening in this region of the spectrum was expected since the measurements were performed in a powdered sample. In spite of that, 
we can observe two shoulders at 710 and $750 \mathrm{~nm}$ in the inset of Figure 1. Finally, the Laporte forbidden $\mathrm{Cu}^{\mathrm{II}} \mathrm{d} \rightarrow \mathrm{d}$ transition is expected to fall close to $560 \mathrm{~nm}$ as in the $\left(\mathrm{Bu}_{4} \mathrm{~N}\right)_{2}[\mathrm{Cu}($ opba $)]$ precursor, even though hidden under the band at $540 \mathrm{~nm}$ of $\mathrm{ttf}^{\circ}$.

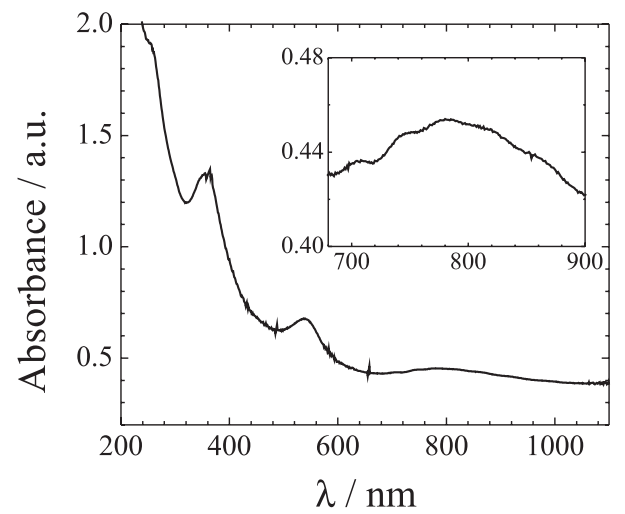

Figure 1. UV-Vis-NIR spectrum of $[\mathrm{ttf}]_{2}[\mathrm{Cu}(\mathrm{opba})] \cdot \mathrm{H}_{2} \mathrm{O}$ in $\mathrm{KBr}$ pressed pellets (concentration: $4 \mathrm{ppm}$ ).

The infrared and Raman spectra can provide some useful information on the nature of the ttf molecule in charge-transfer compounds. ${ }^{31,32}$ The band observed at $830 \mathrm{~cm}^{-1}$ in the IR spectrum (Figure S1) was assigned to a C-S stretching vibration, the $\mathrm{b}_{1 \mathrm{u}}\left(\mathrm{v}_{16}\right)$ mode, of $\mathrm{ttf}^{\cdot+}$ species. Such mode occurs at $781 \mathrm{~cm}^{-1}$ in neutral ttf. This great shift $\left(\Delta=+49 \mathrm{~cm}^{-1}\right)$ to higher frequencies in $\mathrm{ttf}^{\circ+}$ is a consequence of changes in the length and order of the C-S bond caused by ionization effects. ${ }^{27}$ The strong bands at 1350 and $490 \mathrm{~cm}^{-1}$ were assigned to stretching of the central $\mathrm{C}=\mathrm{C}$ double bonds, $\mathrm{a}_{\mathrm{g}}\left(v_{3}\right)$ mode, and to stretching of C-S bonds adjacent to the central ethylenic bond, ${ }^{27} \mathrm{a}_{\mathrm{g}}\left(\mathrm{v}_{6}\right)$ mode, respectively. These modes are inactive in the IR spectrum by selection rules. However, they are strongly coupled with the charge transfer transitions in a molecular radical dimer $\left(\mathrm{ttf}{ }^{\circ}\right)_{2}$, that permits a vibronic intensity borrowing from the CT transition by the vibrational modes of the dimer corresponding to out-of-phase coupling of the originally infrared-inactive $\mathrm{a}_{\mathrm{g}}$ modes. ${ }^{31}$ The main bands that confirm the presence of the $[\mathrm{Cu}(\mathrm{opba})]^{2-}$ anion occur at $440 \mathrm{~cm}^{-1}$, assigned to $v(\mathrm{Cu}-\mathrm{O})$, and at $1645 \mathrm{~cm}^{-1}$, assigned to $\mathrm{v}(\mathrm{C}=\mathrm{O})$.

The Raman spectrum is showed in Figure 2. The most important information is the presence of a pair of bands with strong intensities at 487 and $506 \mathrm{~cm}^{-1}\left(\mathrm{a}_{\mathrm{g}}\right.$ mode $\left.\mathrm{v}_{6}\right)$. Compounds that present only dimeric species as $[\mathrm{ttf}] \mathrm{Cl}$ and (ttf) $)_{3}\left(\mathrm{BF}_{4}\right)^{25}$ have one band in this region of the Raman spectra. This trend can possibly be explained owed to symmetry loss of the dimeric species caused by crystalline packing or due to the presence of two different chemical species, i.e., $\left(\mathrm{ttf}^{\circ+}\right)$ monomer and $\left(\mathrm{ttf}^{\cdot+}\right)_{2}$ dimer. The latter has been observed for (bedt-ttf) $\mathrm{Br}^{33}$

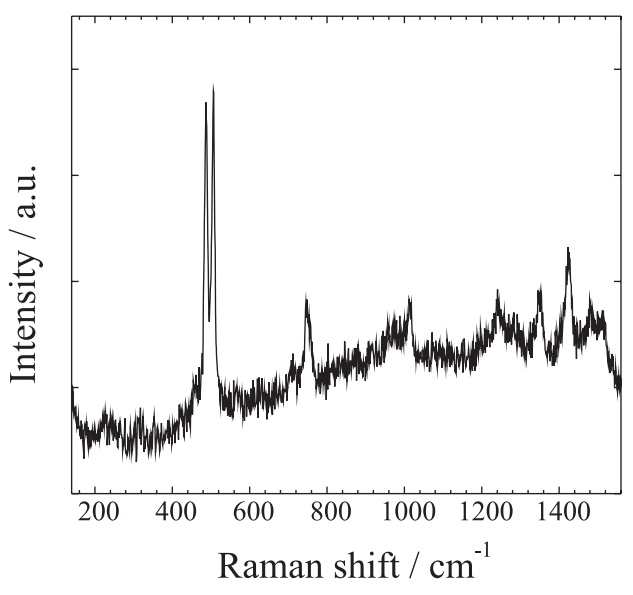

Figure 2. Raman spectrum of $[\mathrm{ttf}]_{2}[\mathrm{Cu}(\mathrm{opba})] \cdot \mathrm{H}_{2} \mathrm{O}$ (powdered sample).

The conductivity properties of $[\mathrm{ttf}]_{2}[\mathrm{Cu}(\mathrm{opba})] \cdot \mathrm{H}_{2} \mathrm{O}$ were studied by impedance spectroscopy (IS) and linear voltammetry (LV). The I-V curves showed linearity between $-10 \mathrm{~V}$ and $+10 \mathrm{~V}$ in agreement with an ohmic behavior of both material and contacts. The slope value locates this material in the semiconductor range (dc conductivity, $\sigma_{\mathrm{dc}}$, about $10^{-4} \mathrm{~S} \mathrm{~cm}^{-1}$ at room temperature). On the other hand, the impedance response in Nyquist plane consisted of a semicircle equivalent to a (RC) parallel electrical circuit accounting for electrical conduction and dielectric polarization mechanisms occurring in the cell (Figure 3). Surprisingly, an increase of the overall conductivity (deduced from $\mathrm{R}_{\mathrm{LF}}$ ) was observed proportionally to dc bias independently of the signal and with a linear $\sigma_{\mathrm{LF}}-\mathrm{E}$ relationship (Figure 4). In addition, $\sigma_{\mathrm{LF}}$ was found to be one order of magnitude lower than $\sigma_{\mathrm{dc}}$, suggesting that the dc polarization effect could be related to some kind of interfacial phenomenon (different electrical contacts). However, at low temperature (100 K for instance) the conductivity range is in the same order of magnitude in both cases (about $10^{-11} \mathrm{~S} \mathrm{~cm}^{-}$ ${ }^{1}$ ), which rules out the possibility of interfacial contributions to the impedance response. Moreover, the dc polarization effect persisted (Figure 3 between 0 and $\pm 1.5 \mathrm{~V}$ ) suggesting that, at least at low temperature, $\sigma_{\mathrm{LF}}$ represents the intrinsic conductivity of the material with a possible dependence upon dc polarization. This phenomenon has already been reported for molecular semiconductors, particularly for charge-transfer complexes. ${ }^{34}$

Figure 5 exhibits the dc conductivity behavior $\left(\sigma_{\mathrm{dc}}\right)$ of [ttf $]_{2}[\mathrm{Cu}(\mathrm{opba})] \cdot \mathrm{H}_{2} \mathrm{O}$ derived from $\mathrm{LV}$ measurements as a function of temperature between 4 and $300 \mathrm{~K}$. A typical semiconductor behavior is observed since the conductivity increases with temperature from $5.3 \times 10^{-16} \mathrm{~S} \mathrm{~cm}^{-1}(4 \mathrm{~K})$ to $1.2 \times 10^{-4} \mathrm{~S} \mathrm{~cm}^{-1}(300 \mathrm{~K})$.

The relaxation time, calculated by $\tau_{\mathrm{R}}=\mathrm{R}_{\mathrm{LF}} \mathrm{CPE}_{\max }$, decreases with the increase of temperature as already 


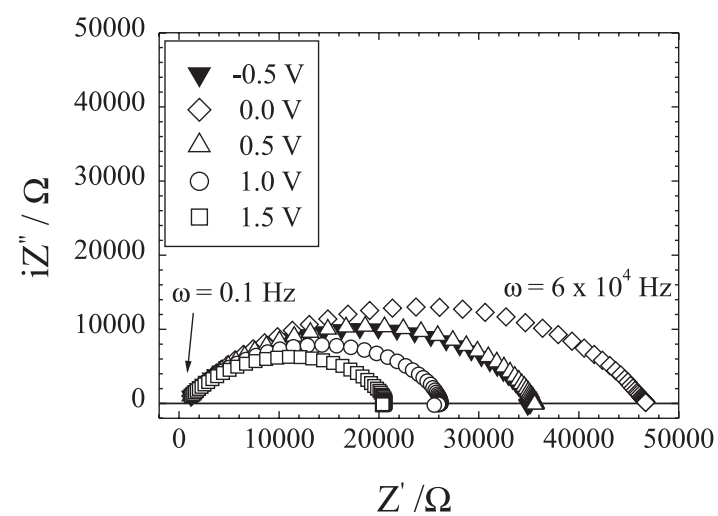

Figure 3. Room temperature Nyquist plots at $-0.5 ; 0.0 ; 0.5 ; 1.0$ and $1.5 \mathrm{~V}(\mathrm{dc})$ for $[\mathrm{ttf}]_{2}[\mathrm{Cu}(\mathrm{opba})] \cdot \mathrm{H}_{2} \mathrm{O}$ pellets.
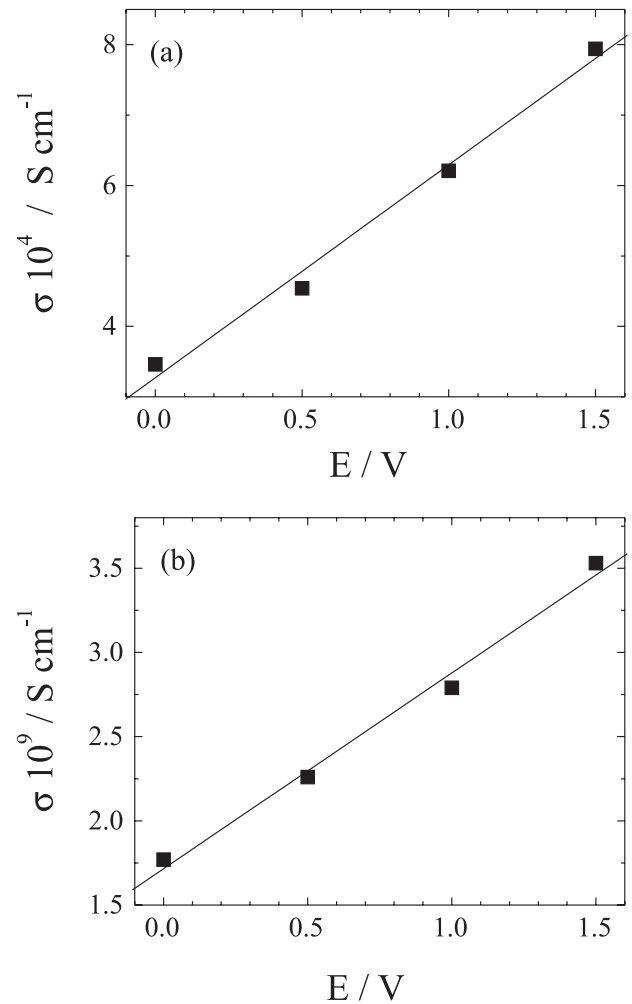

Figure 4. Conductivity $\sigma_{\mathrm{LF}}$ dependence of the potential from IS technique at $300 \mathrm{~K}$ (a) and $89 \mathrm{~K}$ (b) for $[\mathrm{ttf}]_{2}\left[\mathrm{Cu}(\right.$ opba) $] \cdot \mathrm{H}_{2} \mathrm{O}$.

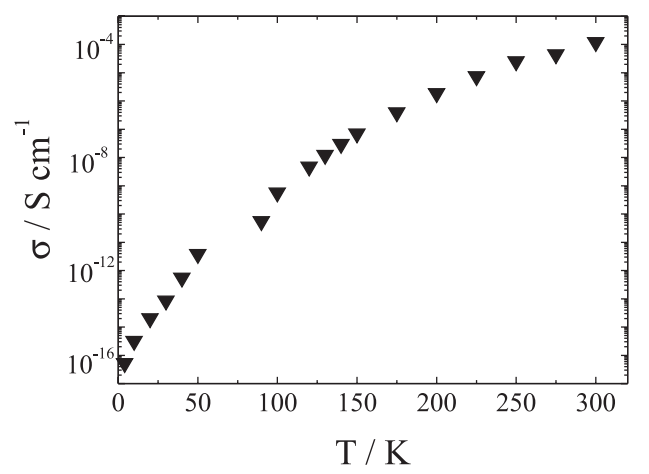

Figure 5. Temperature dependence of conductivity $\sigma_{\mathrm{dc}}$ derived from LV measurements for $[\mathrm{ttf}]_{2}[\mathrm{Cu}($ opba $)] \cdot \mathrm{H}_{2} \mathrm{O}$. reported for other molecular semiconductors..$^{35}$ Below $100 \mathrm{~K}$, a drastic increase of the relaxation time occurs, and the corresponding value is of the order of 1300 times the value obtained at $300 \mathrm{~K}$.

Figure 6 shows the thermal dependence of the conductivity (Arrhenius plot) within the 4-300 K temperature range obtained by I-V measurements. The conductivity could be adjusted by the classical expression from equation 1.

$\sigma=\sigma_{0} \exp \left(\frac{-E_{a}}{\mathrm{kT}}\right)$

where $\sigma_{0}$ is a pre-exponential factor and $\mathrm{E}_{\mathrm{a}}$ is the activation energy. Interestingly, a decrease of the activation energy with temperature was noted changing from $158 \mathrm{meV}$ in the $300-90 \mathrm{~K}$ range to $2 \mathrm{meV}$ in the $20-4 \mathrm{~K}$ temperature range. Such behavior can be originated by a system consisting of an intrinsic semiconductor at high temperatures and an extrinsic (p-type) semiconductor at low temperatures. ${ }^{36} \mathrm{In}$ the intrinsic region, the increase of temperature promotes the electrons for the conduction band and the number of current-carrying species increases exponentially as well the conductivity. This is compatible with the hypothesis of presence of dimers $\left(\mathrm{ttf}^{\circ+}\right)_{2}$ in stacks, and the energy of activation of $158 \mathrm{meV}$ being related to the supermolecular HOMO-LUMO energy gap. The extrinsic region at low temperatures results from sample doping with species that provide either electrons or holes. For $[\mathrm{ttf}]_{2}[\mathrm{Cu}($ opba $)] \cdot \mathrm{H}_{2} \mathrm{O}$, a probable source of doping is an internal contamination process through the disproportionation $2 \mathrm{tff}^{\circ+} \rightarrow \mathrm{tff}^{0}+\mathrm{ttf}^{2+}$, which is well described in the literature. For single crystals of (ttf)tcnq, the concentration of these impurities can reach $12 \% .{ }^{37}$ At low temperatures, the concentration of carriers generated by impurities is much greater than the thermally generated intrinsic carriers, and the effect of reduction of mobility caused by electron-phonons collisions is small.

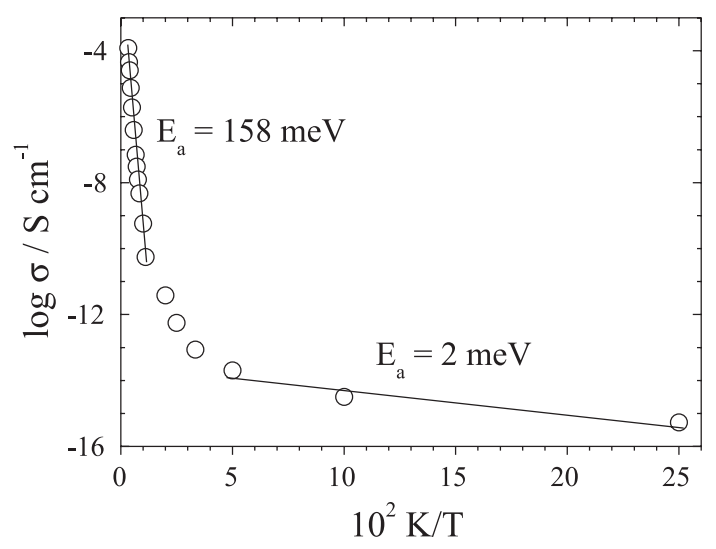

Figure 6. Arrhenius plot of electrical conductivity versus temperature for $[\mathrm{ttf}]_{2}[\mathrm{Cu}(\mathrm{opba})] \cdot \mathrm{H}_{2} \mathrm{O}$. 
Since the carrier concentration is now independent of the temperature, the electron conduction $\sigma$ shows a slight decrease upon cooling owed to the very small activation energy of $2 \mathrm{meV}$. Other sources of impurities cannot be discarded.

The EPR spectra of $[\mathrm{ttf}]_{2}[\mathrm{Cu}(\mathrm{opba})] \cdot \mathrm{H}_{2} \mathrm{O}$ present two lines that cannot be separated by deconvolution. Figure 7 shows the spectra at 300 and $16 \mathrm{~K}$ and a single Lorentzian fitting. In agreement with the results from the literature,,$^{20}$ the signal is typically of $\mathrm{Cu}^{\mathrm{II}}$ (located spins, $\mathrm{S}=1 / 2$ ) superposed to the signal of $\mathrm{ttf}^{*+}$. The latter remains almost unchanged with the decrease of temperature. Since radical cations in a dimer as $\left(\mathrm{ttf}^{\circ}\right)_{2}$ with strong antiferromagnetic (AF) coupling are EPR silent, ${ }^{32,38,39}$ the narrow signal in the EPR spectra indicates that $[\mathrm{ttf}]_{2}[\mathrm{Cu}(\mathrm{opba})] \cdot \mathrm{H}_{2} \mathrm{O}$ contains species like $\mathrm{ttf}^{\bullet+}$.
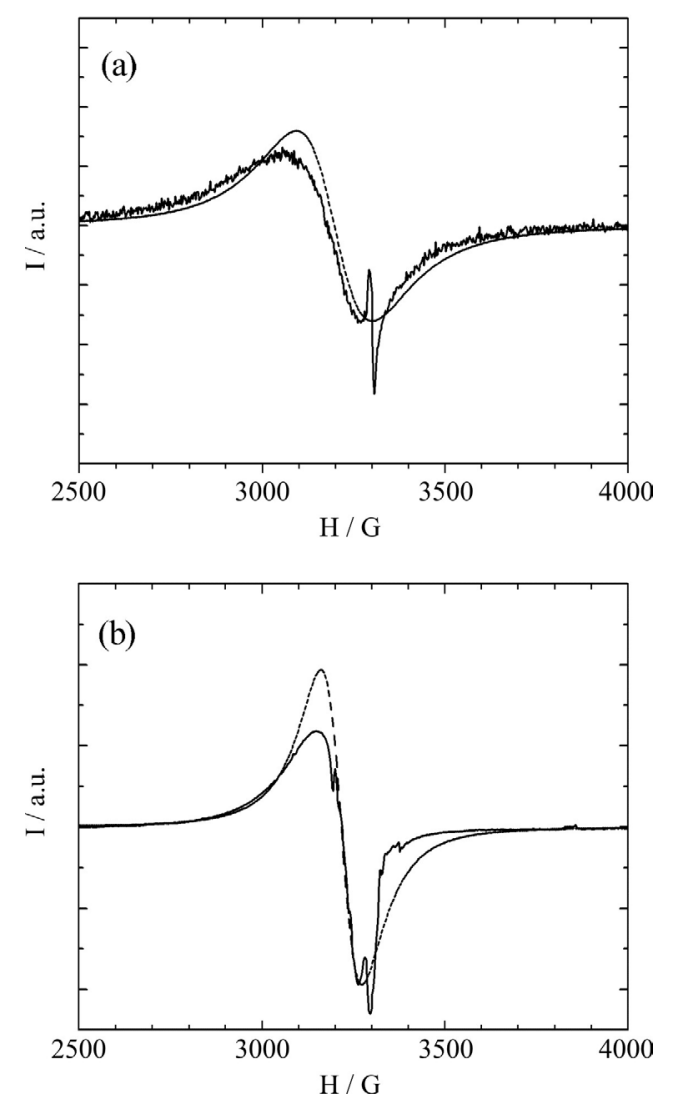

Figure 7. EPR signal of powdered $[\mathrm{ttf}]_{2}[\mathrm{Cu}(\mathrm{opba})] \cdot \mathrm{H}_{2} \mathrm{O}$ and Lorentzian fitting (dotted line) at $300 \mathrm{~K}$ (a) and at $16 \mathrm{~K}$ (b).

Figure 8 shows the thermal dependence of the EPR normalized spin susceptibility, $\chi_{\mathrm{T}} / \chi_{300}=\left(\Delta \mathrm{H}_{\mathrm{pp}}\right)^{2} \mathrm{I}$, where $\Delta \mathrm{H}_{\mathrm{pp}}$ is the peak-to-peak linewidth and I is the amplitude of the signal. ${ }^{40}$ It is important to note that the Lorentzian fitting is dominated by the $\mathrm{Cu}^{\mathrm{II}}$ signal. The spin susceptibility between 300 and $16 \mathrm{~K}$ was fitted with the Curie-Weiss equation 2 , $\chi_{\text {spin }}=\frac{\mathrm{C}}{(\mathrm{T}+\theta)}$

where $\mathrm{C}=\mathrm{S}(\mathrm{S}+1) \mathrm{Ng}^{2} \beta^{2} / 3 \mathrm{k}_{\mathrm{B}}$, and $\theta$ is the nonzero Weiss term or Weiss constant. The fitting (full line in Figure 8) leads to a $\theta$ value of $-12 \mathrm{~K}$ indicating $\mathrm{AF}$ interaction among the paramagnetic centers.

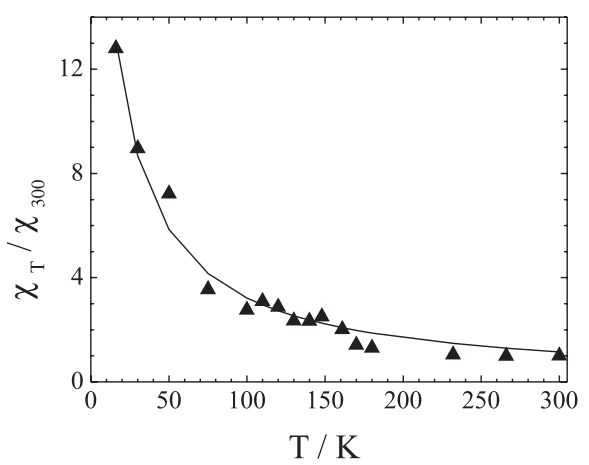

Figure 8. Temperature dependence of the normalized spin susceptibility for $[\mathrm{ttf}]_{2}\left[\mathrm{Cu}(\right.$ opba) $] \cdot \mathrm{H}_{2} \mathrm{O}$ with the best fitting to Equation 2 (full line).

Figure 9 shows the thermal dependence of the $\Delta \mathrm{H}_{\mathrm{pp}}$ for powdered $[\mathrm{ttf}]_{2}[\mathrm{Cu}(\mathrm{opba})] \cdot \mathrm{H}_{2} \mathrm{O}$. The values are nearly constant (about $120 \mathrm{G}$ ) below $90 \mathrm{~K}$ and increase linearly above this temperature until $220 \mathrm{G}$ at $300 \mathrm{~K}$. This behavior is close to that of single crystals of $\left[(\text { bedt-ttf })_{2} \mathrm{Cu}\left(\mathrm{CF}_{3}\right)_{4}\right]^{31}$ and [(bedt-ttf) $\left.\mathrm{Zn}(\mathrm{SCN})_{3}\right] .{ }^{40}$ It is well established that the $\Delta \mathrm{H}_{\mathrm{pp}}$ magnitude depends on the spin-orbit coupling and dipolar interactions, which cause broadening, and magnetic exchange, which affords sharpness. ${ }^{42,43}$ These factors explain the linewidth behavior for $[\mathrm{ttf}]_{2}[\mathrm{Cu}(\mathrm{opba})] \cdot \mathrm{H}_{2} \mathrm{O}$. Between 300 and $90 \mathrm{~K}$ the linewidth decreases owe to the reduction of spin-orbit coupling and increase of the magnetic exchange. Below $90 \mathrm{~K}$, the linewidth is independent of the temperature, probably due to a competition with the increase of dipolar interactions.

The temperature dependence of the magnetic susceptibility of $[\mathrm{ttf}]_{2}[\mathrm{Cu}(\mathrm{opba})] \cdot \mathrm{H}_{2} \mathrm{O}$ is shown in Figure 10

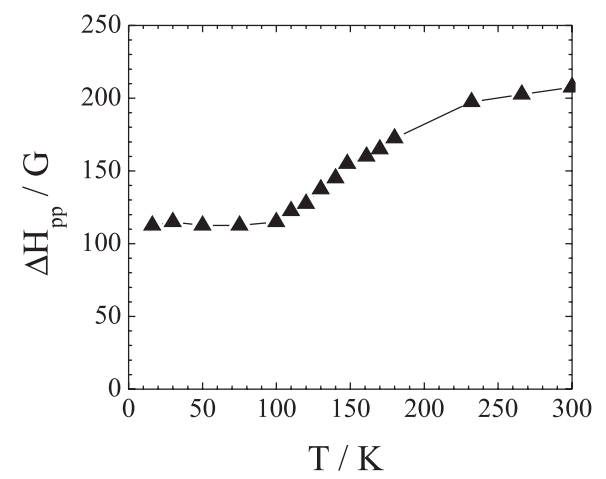

Figure 9. Temperature dependences of the EPR line width for $[\mathrm{ttf}]_{2}[\mathrm{Cu}($ opba $)] \cdot \mathrm{H}_{2} \mathrm{O}$. 
in the form of the $\chi_{\mathrm{M}} \mathrm{T}$ versus $\mathrm{T}$ plot, being $\chi_{\mathrm{M}}$ the molar magnetic susceptibility. At room temperature $\chi_{\mathrm{M}} \mathrm{T}$ is equal to $1.05 \mathrm{emu} \mathrm{K} \mathrm{mol}^{-1}$, which is slightly below what would be anticipated for three uncoupled magnetic centers with $S=1 / 2$. In fact, the value calculated by the spin-only formulae for two radical cations and one $\mathrm{Cu}^{\mathrm{II}}$ ion is $1.1 \mathrm{emu} \mathrm{K} \mathrm{mol}{ }^{-1}$. When the sample is cooled, $\chi_{\mathrm{M}} \mathrm{T}$ decreases slowly and reaches a value of $0.13 \mathrm{emu} \mathrm{K} \mathrm{mol}{ }^{-1}$ at $4 \mathrm{~K}$, the lowest temperature investigated. This behavior makes evident the presence of AF interactions in the compound. Furthermore, the curve is not characteristic for a trinuclear compound as $\mathrm{ttf} \cdots \mathrm{Cu} \cdots \mathrm{ttf}$, neither for a dinuclear one with an isolated magnetic center. In this last case, a value of 0.375 emu $\mathrm{K} \mathrm{mol}^{-1}$, at least, is expected for $\chi_{\mathrm{M}} \mathrm{T}$ in the ground state at low temperatures.

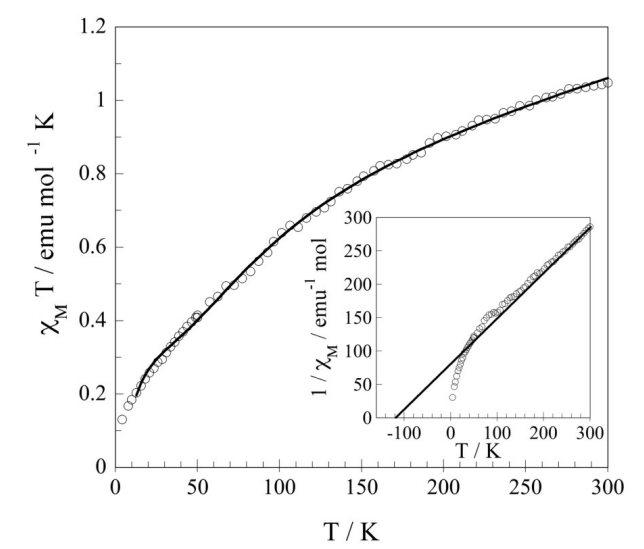

Figure 10. $\chi_{\mathrm{M}} \mathrm{T}$ versus $\mathrm{T}$ plot at $\mathrm{H}=50$ Oe for $[\mathrm{ttf}]_{2}[\mathrm{Cu}(\mathrm{opba})] \cdot \mathrm{H}_{2} \mathrm{O}$ (full line is the fitting from equation 4). Inset: plot of $1 / \chi_{M}$ versus $\mathrm{T}$.

Magnetic data can furnish more structural information on $[\mathrm{ttf}]_{2}[\mathrm{Cu}($ opba $)] \cdot \mathrm{H}_{2} \mathrm{O}$ by application of several models. The first one is based on the plot of $1 / \chi_{\mathrm{M}}$ versus temperature. At high temperature, the data show if the compound follows a Curie law since, in this case, a straight line of slope 1/C will pass through the origin $(0 \mathrm{~K})$. For $[\mathrm{ttf}]_{2}[\mathrm{Cu}($ opba $)] \cdot \mathrm{H}_{2} \mathrm{O}$, using data of the range $200-300 \mathrm{~K}$, the extrapolation affords a $\theta$ value of $-120 \mathrm{~K}$ as shown in the inset of Figure 10. This value demonstrates that strong $\mathrm{AF}$ interactions are present and that they are operative even at room temperature.

A second model considering a dimer $\left(\mathrm{ttf}^{\circ+}\right)_{2}$, that usually presents AF coupling in function of the $\pi-\pi$ interactions, and the $\mathrm{Cu}^{\mathrm{II}}$ ions (also being not magnetically isolated) has been tested. A data fitting in the $300-4 \mathrm{~K}$ temperature range was obtained with equation 3 ,

$$
\chi_{\mathrm{M}}=\frac{\mathrm{C}}{(\mathrm{T}-\theta)}+\left(\frac{2 \mathrm{~N}_{\mathrm{a}} \mathrm{g}_{2}^{2} \beta^{2}}{\mathrm{k}}\right)\left[\frac{1}{3+\exp \left(\frac{-\mathrm{J}}{\mathrm{kT}}\right)}\right]
$$

where the first term is a general contribution from CurieWeiss and the second term is to take in account the dimer ${ }^{44}$ contribution ( $\mathrm{g}_{2}$ was fixed in 2.0). The parameters obtained for $\mathrm{S}=1 / 2$ were $\mathrm{g}_{1}=2.1, \theta=-10.3 \mathrm{~K}, \mathrm{~J}=-165 \mathrm{~cm}^{-1}$, and correlation factor $\mathrm{R}=6.6 \times 10^{-4}$, where $\mathrm{R}=\Sigma\left[\left(\chi_{\mathrm{M}} \mathrm{T}\right)_{\mathrm{obs}}\right.$ $\left.\left(\chi_{\mathrm{M}} \mathrm{T}\right)_{\text {calc }}\right]^{2} / \Sigma\left[\left(\chi_{\mathrm{M}} \mathrm{T}\right)_{\text {obs }}\right]$. It is worth to note that the first Curie-Weiss term can be related to $\mathrm{Cu} \cdots \mathrm{Cu}$ or $\mathrm{Cu} \cdots \mathrm{ttf}{ }^{*+}$ interactions. The $\theta$ value is in accordance with that obtained by EPR fitting $(\theta=-12 \mathrm{~K})$ indicating weak interactions. In contrast, the magnetic coupling $(J)$ attributed to the dimer is very strong as anticipated. In addition, a comparison with the first model shows that there is a good agreement: a value of $-120 \mathrm{~K}$ for the interactions is $-172 \mathrm{~cm}^{-1}$ in the units conversion.

Besides other approaches that were ruled out, ${ }^{45} \mathrm{a}$ third, more elaborated model based on equation 4 is described here. ${ }^{46}$

$\chi_{\mathrm{M}}=\left(\frac{\mathrm{N}_{\mathrm{a}} \mathrm{g}_{1}^{2} \beta^{2}}{\mathrm{kT}}\right)\left[\frac{0.25+0.14995\left(\frac{\mathrm{J}_{1}}{\mathrm{~T}}\right)+0.30094\left(\frac{\mathrm{J}_{1}}{\mathrm{~T}}\right)^{2}}{1+1.9862\left(\frac{\mathrm{J}_{1}}{\mathrm{~T}}\right)+0.68854\left(\frac{\mathrm{J}_{1}}{\mathrm{~T}}\right)^{2}+6.0626\left(\frac{\mathrm{J}_{1}}{\mathrm{~T}}\right)^{3}}\right]+\left(\frac{2 \mathrm{~N}_{\mathrm{a}} \mathrm{g}_{2}^{2} \beta^{2}}{\mathrm{kT}}\right)\left[\frac{1}{3+\exp \left(\frac{-\mathrm{J}_{2}}{\mathrm{kT}}\right)}\right]$

In this model, the first term is for an antiferromagnetic $\mathrm{Cu}^{\mathrm{II}} \mathrm{chain}^{47,48}$ and the second term is for a dimer of radicals, with their respective coupling constants $J_{1}$ and $J_{2}$. The fitting has furnished $J_{1}=-10.1 \mathrm{~cm}^{-1}$ and $J_{2}=-186 \mathrm{~cm}^{-1}$, $\mathrm{g}_{1}=2.278\left(\mathrm{~g}_{2}=2.0\right.$, fixed for radical cation $\left.\mathrm{ttf}^{\circ}\right)$ and an excellent correlation factor: $\mathrm{R}=6.7 \times 10^{-6}$. It is worth to note that the $J_{1}$ absolute value is close to the coupling constant $J_{\text {Cu-Rad }}\left(8 \mathrm{~cm}^{-1}\right)$ found in the $\left\{[\mathrm{Cu}(\text { opba })]^{2-\ldots} \cdot \operatorname{Rad}\right\}^{\mathrm{n}-}$ chain (where $\mathrm{Rad}$ is a radical cation) described in the literature. ${ }^{49}$

\section{Conclusions}

To the best of our knowledge, the system $[\mathrm{ttf}]_{2}[\mathrm{Cu}(\mathrm{opba})] \cdot \mathrm{H}_{2} \mathrm{O}$ presented here is the first oxamatobased charge transfer salt with tetrathiafulvalene. The synthesis process is simple and quick, avoiding some usual problems in the preparation of the molecular materials as electrocrystallization over long periods and attainment of small amounts of samples. Although single crystals are not available, a full characterization of the actual molecular semiconductor was accomplished by a combination of different techniques. Successively, through EPR and dc magnetic susceptibility analyses, it was shown that the coupling scheme of the three species with spin $S=1 / 2$ of the compound had no correspondence with the trinuclear $\{\mathrm{ttf} \cdots \mathrm{Cu} \cdots \mathrm{ttf}\}$ neither to a hybrid composed by a dimer $\left(\mathrm{ttf}^{\circ+}\right)_{2}$ and a $\{\mathrm{Cu} \cdots \mathrm{Cu}\}$ AF system. The mathematical model that affords the best least square fitting indicated that the $[\mathrm{ttf}]_{2}[\mathrm{Cu}(\mathrm{opba})] \cdot \mathrm{H}_{2} \mathrm{O}$ structure can be composed of two stacks, one positively charged and built of piles of $\left(\mathrm{ttf}^{\cdot+}\right)_{2}$ 
dimers (with intradimer AF coupling $J_{2}=-186 \mathrm{~cm}^{-1}$ ) and the second one consisting of a $\left\{[\mathrm{Cu}(\mathrm{opba})]^{2-\ldots} \ldots \mathrm{ttf}^{{ }^{+}}\right\}^{\mathrm{n}-}$ chain (AF coupling with $J_{1}=-10.1 \mathrm{~cm}^{-1}$ ).

The compound described herein presents very interesting features for dual-action materials, essential for the molecular spintronics field, but also a capability to aggregate other functionalities, such as optical properties, solubility or biocompability, to generate multiproperty systems. Indeed, it displays some advantages over other donor-acceptor/paramagnetic metal ions hybrids like ttf/oxalate compounds, in view of the flexibility to modify the "organic moiety" of the proligand opba (by addition of substituents) and the possibility to include other metal ions into the molecular system by means of the carbonyl oxygen atoms.

\section{Supplementary Information}

Supplementary data (Figure S1) are available free of charge at http://jbcs.sbq.org.br, as a pdf file.

\section{Acknowledgments}

This work was supported by the Brazilian agencies: Coordenação de Aperfeiçoamento de Pessoal de Nível Superior (CAPES), Fundação de Amparo à Pesquisa do Estado de Minas Gerais (FAPEMIG), and Conselho Nacional de Desenvolvimento Científico e Tecnológico (CNPq). The authors are grateful to Prof. K. Krambrock (Departamento de Física-UFMG, Brazil) for the EPR measurements, and to Prof. M. L. A. Temperini (Instituto de Química-USP, Brazil) for the Raman data.

\section{References}

1. Wudl, F.; Smith, G. M.; Hufnagel, E. J.; J. Chem. Soc. D, Chem. Commun. 1970, 1453.

2. Wudl, F.; Wobschal, D; Hufnagel, E. J.; J. Am. Chem. Soc. 1972, 94, 670 .

3. Ferraris, J.; Walatka, V.; Perlstei, Jh.; Cowan, D. O.; J. Am. Chem. Soc. 1973, 95, 948.

4. Coronado, E.; Day, P.; Chem. Rev. 2004, 104, 5419.

5. Williams, J. M.; Kini, A. M.; Wang, H. H.; Carlson, K. D.; Geiser, U.; Montgomery, L. K.; Pyrka, G. J.; Watkins, D. M.; Kommers, J. M.; Boryschuk, S. J.; Crouch, A. V. S.; Kwok, W. K.; Schirber, J. E.; Overmyer, D. L.; Jung, D.; Whangbo, M. H.; Inorg. Chem. 1990, 29, 3272.

6. Wang, H. H.; Schlueter, J. A.; Geiser, U.; Williams, J. M.; Naumann, D.; Roy, T.; Inorg. Chem. 1995, 34, 5552.

7. Kahn, O.; Stumpf, H.; Pei, Y.; Sletten, J.; Mol. Cryst. Liq. Cryst. 1993, 233, 231.
8. Stumpf, H. O.; Ouahab, L.; Pei, Y.; Grandjean, D.; Kahn, O.; Science 1993, 261, 447.

9. Pereira, C. L. M.; Doriguetto, A. C.; Konzen, C.; Meira-Belo, L. C.; Leitao, U. A.; Fernandes, N. G.; Mascarenhas, Y. P.; Ellena, J.; Brandl, A. L.; Knobel, M.; Stumpf, H. O.; Eur. J. Inorg. Chem. 2005, 5018.

10. Pereira, C. L. M.; Pedroso, E. F.; Novak, M. A.; Brandl, A. L.; Knobel, M.; Stumpf, H. O.; Polyhedron 2003, 22, 2387.

11. Dias, M. C.; Knobel, M.; Stumpf, H. O.; J. Magn. Magn. Mater. 2001, 226, 1961.

12. Vaz, M. G. F.; Knobel, M.; Speziali, N. L.; Moreira, A. M.; Alcantara, A. F. C.; Stumpf, H. O.; J. Braz. Chem. Soc. 2002, $13,183$.

13. Vaz, M. G. F.; Pedroso, E. F.; Speziali, N. L.; Novak, M. A.; Alcantara, A. F. C.; Stumpf, H. O.; Inorg. Chim. Acta 2001, 326,65 .

14. Cangussu, D.; Nunes, W. C.; Pereira, C. L. M.; Pedroso, E. F.; Mazali, I. O.; Knobel, M.; Alves, O. L.; Stumpf, H. O.; Eur. J. Inorg. Chem. 2008, 3802.

15. Pereira, C. L. M.; Pedroso, E. F.; Stumpf, H. O.; Novak, M. A.; Ricard, L.; Ruiz-Garcia, R.; Riviere, E.; Journaux, Y.; Angew. Chem. Int. Ed. 2004, 43, 955.

16. Souza, G. P.; Konzen, C.; Ardisson, J. D.; De Abreu, H. A.; Duarte, H. A.; Alcantara, A. F. C.; Nunes, W. C.; Macedo, W. A. A.; Knobel, M.; Stumpf, H. O.; J. Braz. Chem. Soc. 2006, 17, 1534 .

17. Baibich, M. N.; Broto, J. M.; Fert, A.; Vandau, F. N.; Petroff, F.; Eitenne, P.; Creuzet, G.; Friederich, A.; Chazelas, J.; Phys. Rev. Lett. 1988, 61, 2472.

18. Moon, K. S.; Fontana, R. E.; Parkin, S. S. P.; Appl. Phys. Lett. 1999, 74, 3690.

19. Coronado, E.; Falvello, L. R.; Galan-Mascaros, J. R.; GimenezSaiz, C.; Gomez-Garcia, C. J.; Lauhkin, V. N.; Perez-Benitez, A.; Rovira, C.; Veciana, J.; Adv. Mater. 1997, 9, 984.

20. Day, P.; Kurmoo, M.; Mallah, T.; Marsden, I. R.; Friend, R. H.; Pratt, F. L.; Hayes, W.; Chasseau, D.; Gaultier, J.; Bravic, G.; Ducasse, L.; J. Am. Chem. Soc. 1992, 114, 10722.

21. Coronado, E.; Galan-Mascaros, J. R.; Gomez-Garcia, C. J.; Laukhin, V.; Nature 2000, 408, 447.

22. Graham, A. W.; Kurmoo, M.; Day, P.; J. Chem. Soc., Chem. Commun. 1995, 2061.

23. Kurmoo, M.; Graham, A. W.; Day, P.; Coles, S. J.; Hursthouse, M. B.; Caulfield, J. L.; Singleton, J.; Pratt, F. L.; Hayes, W.; Ducasse, L.; Guionneau, P.; J. Am. Chem. Soc. 1995, 117, 12209.

24. Dias, M. C.; Stumpf, H. O.; Sansiviero, M. T. C.; Pernaut, J. M.; Matencio, I.; Knobel, M.; Cangussu, D.; Quim. Nova 2007, 30, 904.

25. Wudl, F.; J. Am. Chem. Soc. 1975, 97, 1962.

26. Boukamp, B. A.; Solid State Ionics 1986, 20, 31.

27. Bozio, R.; Zanon, I.; Girlando, A.; Pecile, C.; J. Chem. Phys. 1979, 71, 2282. 
28. Torrance, J. B.; Scott, B. A.; Welber, B.; Kaufman, F. B.; Seiden, P. E.; Phys. Rev. B 1979, 19, 730.

29. Iyoda, M.; Hasegawa, M.; Miyake, Y.; Chem. Rev. 2004, 104, 5085.

30. Yakushi, K.; Nishimura, S.; Sugano, T.; Kuroda, H.; Ikemoto, I.; Acta Crystallogr. Sect. B, Struct. Commun. 1980, 36, 358.

31. Bellitto, C.; Bonamico, M.; Fares, V.; Imperatori, P.; Patrizio, S.; J. Chem. Soc., Dalton Trans. 1989, 719.

32. Siedle, A. R.; Candela, G. A.; Finnegan, T. F.; Vanduyne, R. P.; Cape, T.; Kokoszka, G. F.; Woyciejes, P. M.; Hashmall, J. A.; Inorg. Chem. 1981, 20, 2635.

33. Kozlov, M. E.; Pokhodnia, K. I.; Yurchenko, A. A.; Spectrochim. Acta, Part A 1989, 45, 437.

34. Hasanudin; Kuroda, N.; Kagayama, T.; Sugimoto, T.; Mogi, I.; Watanabe, K.; Motokawa, M.; High Pressure Res. 2002, 22, 251.

35. Ashcroft, N. W.; Mermin, N. D.; Solid State Physics, Saunder College Publishing: New York, 1976.

36. West, A. R.; Solid State Chemistry and its Applications, John Wiley: New York, 1984.

37. Starodub, V. A.; Krivoshei, I. V.; Russ. Chem. Rev. 1982, 51, 764.

38. Coronado, E.; Galan-Mascaros, J. R.; Gimenez-Saiz, C.; Gomez-Garcia, C. J.; Ruiz-Perez, C.; Eur. J. Inorg. Chem. 2003, 2290.

39. Lacroix, P.; Kahn, O.; Valade, L.; Cassoux, P.; Thompson, L. K.; Synth. Met. 1990, 39, 81.
40. Kataev, V.; Winkel, G.; Knauf, N.; Gruetz, A.; Khomskii, D.; Wohlleben, D.; Crump, W.; Hahn, J.; Tebbe, K. F.; Physica B 1992, 179, 24.

41. Komatsu, T.; Kojima, N.; Saito, G.; Solid State Commun. 1997, 103, 519.

42. Bencini, A.; Gatteschi, D.; Electron Paramagnetic Resonance of Exchange Coupled Systems, Springer-Verlag: Berlin, 1990.

43. Drago, R. S.; Physical Methods for Chemists, 2nd ed., Saunders College Publishing: New York, 1992.

44. Bleaney, B.; Bowers, K. D.; Proc. R. Soc. A-Math. Phys. Eng. Sci. 1952, 214, 451.

45. Kahn, O.; Molecular Magnetism, VCH: New York, 1993.

46. Gomez-Garcia, C. J.; Gimenez-Saiz, C.; Triki, S.; Coronado, E.; Lemagueres, P.; Ouahab, L.; Ducasse, L.; Sourisseau, C.; Delhaes, P.; Inorg. Chem. 1995, 34, 4139.

47. Bonner, J. C.; Fisher, M. E.; Phys. Rev. 1964, 135, A640.

48. Brown, D. B.; Donner, J. A.; Hall, J. W.; Wilson, S. R.; Wilson, R. B.; Hodgson, D. J.; Hatfield, W. E.; Inorg. Chem. 1979, 18, 2635.

49. Cador, O.; Vaz, M. G. F.; Stumpf, H. O.; Mathoniere, C.; Kahn, O.; Synth. Met. 2001, 122, 559.

Received: October 8, 2009

Web Release Date: April 22, 2010

FAPESP helped in meeting the publication costs of this article. 


\section{A New Molecular Magnetic Semiconductor Based on Tetrathiafulvalene (ttf) and Oxamato Ligand (opba): [ttf $]_{2}[\mathrm{Cu}(\mathrm{opba})] \cdot \mathrm{H}_{2} \mathrm{O}$}

\section{Mauro C. Dias, ${ }^{a}$ Humberto O. Stumpf, ${ }^{*, b}$ Raquel V. Mambrini, ${ }^{b}$ Tulio Matencio, ${ }^{b}$ Maria} T. C. Sansiviero ${ }^{b}$ and Marcelo Knobel

${ }^{a}$ Coordenadoria de Ciências e Tecnologias Químicas, Centro Federal de Educação Tecnológica do Espírito Santo, 29040-780 Vitória-ES, Brazil

${ }^{b}$ Departamente de Química, ICEx, Universidade Federal de Minas Gerais, 31270-901 Belo Horizonte-MG, Brazil

'Instituto de Física Gleb Wataghin, Universidade Estadual Campinas, 13083-970 Campinas-SP, Brazil

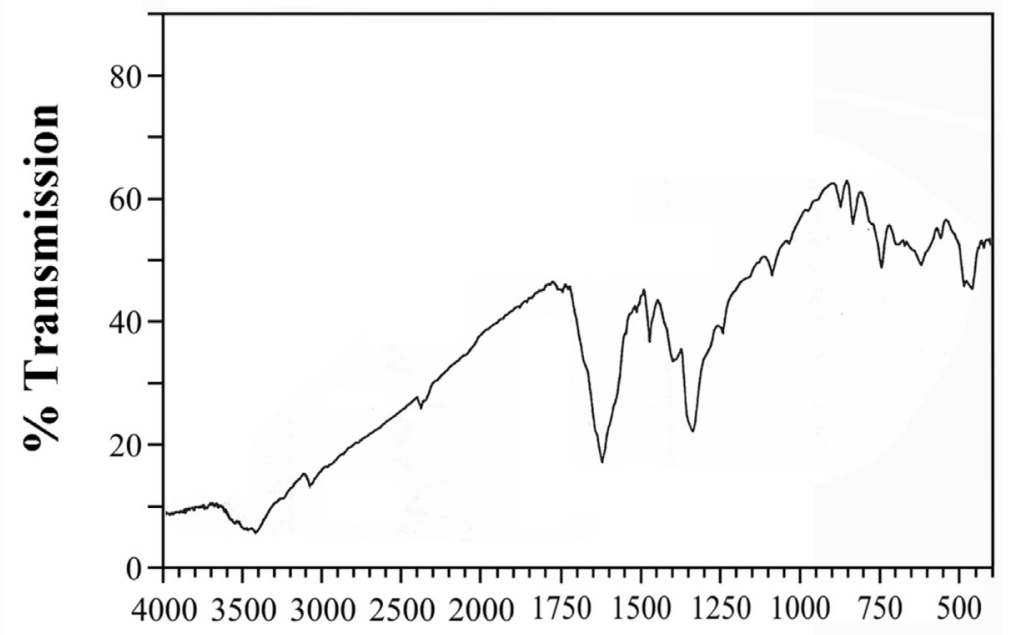

Wavenumber $/ \mathrm{cm}^{-1}$

Figure S1. FTIR spectrum of $[\mathrm{ttf}]_{2}[\mathrm{Cu}(\mathrm{opba})] \cdot \mathrm{H}_{2} \mathrm{O}(\mathrm{KBr}$ pellet $)$. 